\title{
Application of High-Voltage Power Supply on Electrostatic Precipitator
}

\author{
Yan-Jie Li, Yu-Xiang Chen \\ College of Applied Technology, University of Science and Technology Liaoning, Anshan, China \\ Email: li_yanjie@126.com, chenyuxiangf2@163.com
}

How to cite this paper: Li Y.-J. and Chen, Y.-X. (2017) Application of High-Voltage Power Supply on Electrostatic Precipitator. World Journal of Engineering and Technology, 5, 269-274.

https://doi.org/10.4236/wjet.2017.52021

Received: March 21, 2017

Accepted: May 21, 2017

Published: May 24, 2017

Copyright @ 2017 by authors and Scientific Research Publishing Inc. This work is licensed under the Creative Commons Attribution International License (CC BY 4.0).

http://creativecommons.org/licenses/by/4.0/

\begin{abstract}
This article firstly describes the main technical parameters and performance of the high power supply of electrostatic precipitator, and then describes the structure, principle and characteristic of power supply of electrostatic precipitator, and finally analyses the common faults of power supply of electrostatic precipitator in the operation and puts forward the methods of dealing with breakdown. Operation results show that the system is stable and reliable, and overall performance and the efficiency of dust control have been improved significantly. The scheme has been well applied in the field of environmental protection and dust removal.
\end{abstract}

\section{Keywords}

Electrostatic Precipitator, High-Voltage Power Supply, Spark Discharge

\section{Introduction}

Electrostatic precipitator (ESP) plays an important role in the industrial dust pollution control. With the continuous industrial development in our country, more and more attention has been drawn towards the protection of environment. Especially in recent years the PM2.5 is put forward, there are more stringent requirements for the discharge of pollutants. So it is imperative to reform high-voltage power supply of electrostatic precipitator. Traditional electrostatic precipitator rectifier equipment control system often results in multiple faults in operation which contribute to the instability of rectifier devices working condition, such as: slow speed of sparks tracking, unable to take charge measurement and the display of static parameters, low control accuracy etc. Aiming at the existing defects of equipment, high-voltage power supply of electrostatic precipitator has been remodified by using digital signal processor produced by TI company. Until now, electrostatic precipitator is in good working order and the 
dust removal effect has been improved obviously.

\section{Main Technical Indicators and Performance}

\subsection{Main Technical Indicators}

The purpose of improving the power supply of electrostatic precipitator is to obtain more and more high efficiency of dust removal. In general, the output voltage of electrostatic precipitator is higher, according to the working principle of electrostatic precipitator, dust removal effect should be better. But for the electrostatic precipitator electric field, there is always a maximum voltage, once more than the maximum voltage, the dust collector will produce spark discharge. When the spark discharges, the dust removal effect of the dust collector is lost, and the spark discharge can cause a lot of damage to the dust collector itself. Therefore, dust collector at work, precipitator power supply voltage should as far as possible to close to the spark discharge voltage and electrostatic precipitator power supply to be able to quickly judge and deal with the spark discharge, and achieve certain spark rate [1]. When electrostatic precipitators work, the working voltage of power supply should be as high as possible to close to spark discharge voltage, and to achieve a certain spark $\mathrm{r}$ rate. In this paper GGAJ02 high voltage silicon rectifier equipment is classified by the rated output voltage, (secondary voltage) and rated current (secondary current). The secondary rated output voltage is divided into three gears: $60 \mathrm{kv}, 72 \mathrm{kv}, 90 \mathrm{kv}$ three levels. AC input voltage: single-phase $380 \mathrm{v}$; frequency: $50 \mathrm{~Hz}$. All of the electrical operation data and parameters can be displayed on the color touch screen which can not only display the digital information, but can show working mode, such as: spark times per minute, spark occurs, alarm/state, secondary current, etc.

\subsection{Main Technical Performance}

Although the electrostatic precipitator is to achieve the purpose of dust removal by corona discharge, with the increase of the corona power, the dust removal efficiency will be improved. But the voltage between the dust collector and the corona electrode will be affected by the spark discharge in the end, and the corona voltage and corona power cannot be improved at will. First, when the dust collector operating voltage is close to the spark discharge voltage, the dust removal efficiency of the dust collector reaches a maximum value, but with such a high operating voltage, spark discharge frequently occurs in the electric field of the dust collector. The operating voltage between the electrode plate of the dust collector is decreased rapidly to zero, and the dust collector loses the function of removing dust. The second dust is caused by the large current in the dust collector, which is caused by the spark discharge. Large current increases leakage rate. If the spark discharge cannot be handled immediately, the spark discharge will be transformed into the arc discharge which may cause more serious consequences. Therefore, the spark discharge control is also one of the main points in the content. Dynamic spark control performance system has a unique way of detecting spark and arc detection in article which can accurately identify the 
signal strength and realize the whole process of intelligent control of spark by different control methods and variable parameters.

\section{Main Structure and Working Principle}

\subsection{Main Structure}

In the electric dust catcher system, electrical system is mainly composed of high voltage silicon rectifier control cabinet, rectifier transformer and reactor. Digital control is adopted in the system. The structure of the control system is shown in Figure 1, core is digital signal processor produced by TI company. The components of the system exchange information with each other through a digital signal processor [2]. The control of the silicon rectifier transformer dc output voltage is realized through mutual information exchange, communication and data processing process between each part and digital signal processor.

\subsection{Working Principle.}

The high voltage power supply control system adopts the silicon controlled voltage regulating device, which is converted into $220 \mathrm{VAC}$ by entering into a single phase $380 \mathrm{VAC}$, and is input to the controller. When the control system is working, some of the original data and some key data stored during the last shutdown are read out, which is the basis for the control of the conduction angle of the thyristor. The voltage and current signals from the primary and secondary sampling of the boost transformer are filtered to the operational amplifier. The amplified signal is sent to the input of the $\mathrm{A} / \mathrm{D}$ converter, which is converted to the controller by $\mathrm{A} / \mathrm{D}$, The controller is used to analyze the data to judge the operating state of the electric field, and then adjust the conduction angle of the primary side of the main circuit in order to determine the conduction angle of the thyristor. Since the trigger angle of the thyristor is calculated from the positive half of the zero crossing point of the voltage, it is necessary to provide synchronous detection signal simultaneously. Starting from the synchronous phase shift, and finally triggered by the trigger pulse to trigger Silicon controlled. Then, the negative pressure is generated by the step-up transformer of the transformer and the electric field is generated by the electrode to make the electric field work

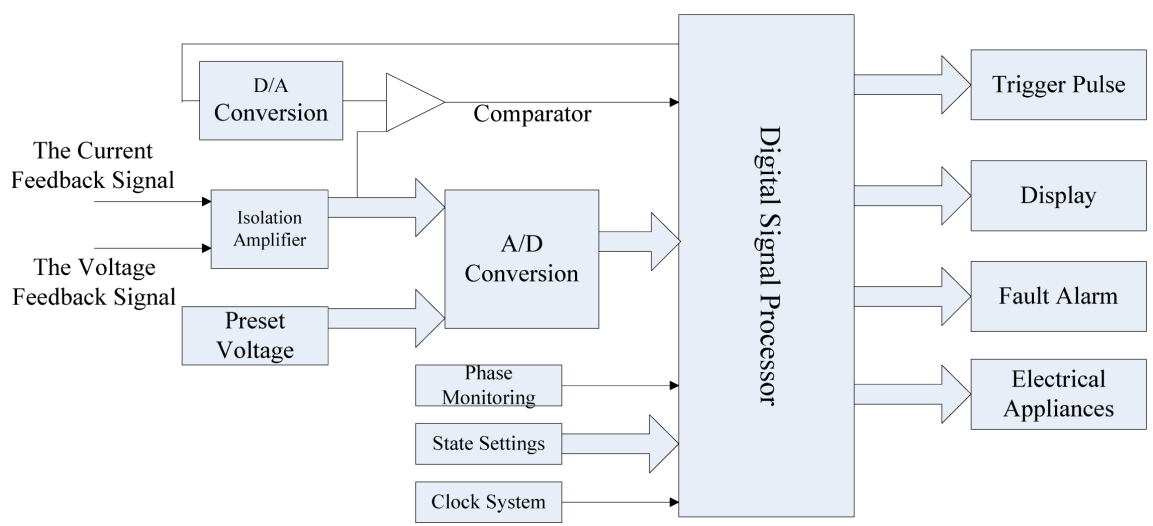

Figure 1. Control system structure. 
in a certain control mode.

When the current drops to zero crossing, the thyristor is switched off automatically. Complete a work cycle. When the electric field breakdown occurs, the spark flashover occurs, and the controller reads the accurate value of the two current.

The spark intensity is determined by software comparison, and the information is taken into account when calculating the phase angle of the thyristor. If the spark discharge phenomenon disappears, it will increase the conduction angle of the silicon controlled rectifier according to the determined spark per minute, until the spark discharge appears again [3]. Repeat the above process. As shown in Figure 2.

\section{Main Characteristic of the Improved High Voltage Power Supply}

\subsection{Control Accuracy and Real-Time Control.}

The system uses the embedded dual core CPU structure design to ensure the control accuracy and real-time control; Data display and keyboard adopt color touch-screen operation that can not only display the various real-time operating mode parameters of the equipment operation and the volt-ampere characteristic curve, but show history running state and alarm data, etc. Examined by password access mechanism, modify and set limit operation parameters through the virtual keyboard for the color touch screen. To ensure the reliability of spark (or arc) tracking control, spark detection circuit of hardware and the software arc detection calculation step are independent of each other.

\subsection{Fault Alarm Fault Handling}

The system has a variety of fault alarm processing functions and the products have system short circuit alarm and fault handling; system open alarm and fault handling; slant thyristor excitation alarm and fault handling; transformer oil temperature, gas overrun alarm and fault handling; user defined alarm and fault handling.

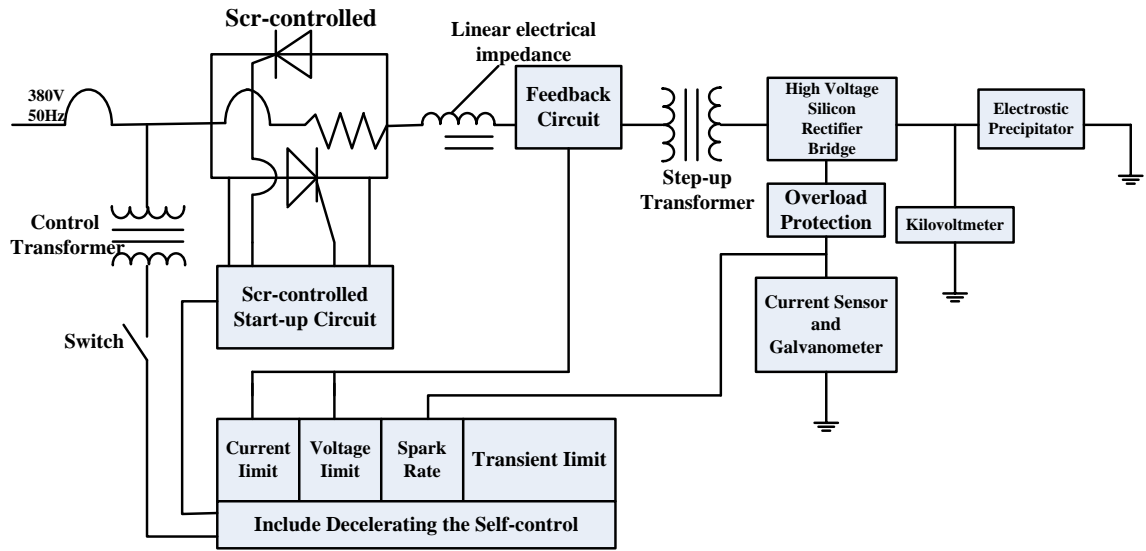

Figure 2. Schematic diagram of major loop of high voltage power supply control system. 


\subsection{Real-Time Control Modes}

The system has a variety of real-time control modes: Tracking control; Peak tracking control; Constant current, constant voltage control; Pulse power supply control; Intermittent power supply control; Arc response control; Flow cut-off control; Step-down vibrating control; Flue gas turbidity meter closed-loop control; Manual and automatic switch control each other and so on. All the control modes mentioned can response separately and can also combine a variety of control functions to meet the demand of the actual operation condition.

\section{Analysis and Treatment for Typical Faults}

\subsection{Analysis and Treatment for Typical Faults One}

Spark discharge phenomenon occurs in electric field of dust collector, but the control system does not detect it; or no spark discharge phenomenon occurs in electric field of dust collector, but the control system detects the spark discharge phenomenon. Such malfunctions are due to the setup problem of Spark detection sensitivity. Adjust the GGAJ02-WJB integrated controller internal circuit board spark sensitivity potentiometer RV, counterclockwise adjustment for spark control sensitivity enhancement, otherwise weakened.

\subsection{Analysis and Treatment for Typical Faults Two}

After operating equipment for a period of time, secondary voltage and secondary current gradually decrease and the dust removal effect becomes weaken. This may be due to the long-term work under a single mode. Steps below can be followed to do adjustment. First, adjust the low voltage control system rapping periodicity set smaller rapping periodicity. Then, increase vibration or change the mode of vibration. Finally, use "step-down shaking" operation mode. After working for a period of time, observe dust removal effect.

\section{Conclusion}

The high-voltage power supply control system is the key to improve dust collection efficiency. Application of the high-voltage power supply of ESP adopts the embedded dual core CPU structure design, which can adjust the voltage effective value according to the situation of the load in time, so as to achieve the best dust removal efficiency. At the same time, electric precipitator system has greatly improved in aspects of reliability and control performance of the electric dust removal system, network communication, intelligent control and human-machine interface operation, etc. As a result, application of the system will get positive applications.

\section{Acknowledgements}

First and foremost, I would like to show my deepest gratitude to Professor K.C. WANG. Conversations with him have been most helpful. I shall extend my thanks to Mr. Also for all his kindness and help. This work has been supported 
by The Applied School of University of Science and Technology Liaoning.

\section{References}

[1] Hu, Z.G., et al. (1998) Electrostatic Precipitator Power Supply Control Technology. North China Electric Power University, Beijing.

[2] Chen, J. (1999) Digital Microcomputer Control High Voltage Electrostatic Dedusting Rectifier Equipment Applications. Shandong Metallurgical.

[3] Liu, Y. (2008) The Research of the Control System of High Voltage Power Supply Electrostatic Precipitators. Master's Thesis, Liaoning University of Science and Technology, Anshan, 18-19.

Submit or recommend next manuscript to SCIRP and we will provide best service for you:

Accepting pre-submission inquiries through Email, Facebook, LinkedIn, Twitter, etc. A wide selection of journals (inclusive of 9 subjects, more than 200 journals)

Providing 24-hour high-quality service

User-friendly online submission system

Fair and swift peer-review system

Efficient typesetting and proofreading procedure

Display of the result of downloads and visits, as well as the number of cited articles

Maximum dissemination of your research work

Submit your manuscript at: http://papersubmission.scirp.org/

Or contactwjet@scirp.org 